NBER WORKING PAPER SERIES

\title{
MEASURING AND INTERPRETING EXPECTATIONS OF EQUITY RETURNS
}

\author{
Jeff Dominitz \\ Charles F. Manski \\ Working Paper 11313 \\ http://www.nber.org/papers/w11313
}

\author{
NATIONAL BUREAU OF ECONOMIC RESEARCH \\ 1050 Massachusetts Avenue \\ Cambridge, MA 02138 \\ May 2005
}

This research was supported in part by NSF Grant SES-0314312. Maria Salgado provided excellent research assistance. We are grateful to the University of Michigan Survey Research Center's Committee for Research Initiatives in the Monthly Survey, which approved placement of the "percent chance" questions on the Survey of Consumers. We are also grateful to Richard Curtin, Principal Investigator of the Survey of Consumers, for his cooperation in this endeavor. Early findings from this research were presented at the 2005 Annual Meeting of the American Economic Association, in the session on Subjective Probability Distributions; we thank Susann Rohwedder for comments. We have subsequently benefitted from the opportunity to present this work in seminars at University College London and Northwestern University. The views expressed herein are those of the author(s) and do not necessarily reflect the views of the National Bureau of Economic Research.

(O2005 by Jeff Dominitz and Charles F. Manski. All rights reserved. Short sections of text, not to exceed two paragraphs, may be quoted without explicit permission provided that full credit, including $\odot$ notice, is given to the source. 
Measuring and Interpreting Expectations of Equity Returns

Jeff Dominitz and Charles F. Manski

NBER Working Paper No. 11313

May 2005

JEL No. G1, D8

\begin{abstract}
We analyze probabilistic expectations of equity returns elicited in the Survey of Economic Expectations in $1999-2001$ and in the Michigan Survey of Consumers in 2002 -2004. Our empirical findings suggest that individuals use interpersonally variable but intrapersonally stable processes to form their expectations. We therefore propose to think of the population as a mixture of expectations types, each forming expectations in a stable but different way. We use our expectations data to learn about the prevalence of several specific types suggested by research in conventional and behavioral finance, but conclude that these types do not adequately explain the diverse expectations held by the population.

Jeff Dominitz

H. John Heinz School of Public Policy and Management

Carnegie Mellon University

5000 Forbes Avenue

Pittsburgh, PA 15213

dominitz@andrew.cmu.edu

Charles F. Manski

Department of Economics

Northwestern University

2001 Sheridan Road

Evanston, IL 60208

and NBER

cfmanski@northwestern.edu
\end{abstract}




\section{$\underline{1 . \text { Introduction }}$}

Expectations of equity returns are widely thought to be central determinants of investment in equities and other assets. However, researchers studying asset markets have only recently begun to measure the expectations that potential investors hold. In the absence of data, basic questions about the nature of expectations have remained open.

There has been particular disagreement about the extent and nature of heterogeneity in beliefs about returns. Much of the finance literature has regarded heterogeneity in beliefs as either non-existent or unimportant. The original formulation of the capital asset price model assumed that all persons hold the same expectations for asset returns (Sharpe, 1964; Lintner, 1965) and subsequent discussions asserted that heterogeneity in expectations would not affect the basic conclusions of that model (Lintner, 1969; Sharpe, 1970). Adherents of the efficient markets hypothesis have contended that prices reveal all privately held information and have concluded that expectations must be homogeneous ex post, even if they are heterogeneous ex ante (Fama, 1970).

Other researchers have argued that heterogeneity in expectations is critical to the functioning of asset markets. This was true of Keynes (1937) and Williams (1938) almost seventy years ago and of Miller (1977) and Mayshar (1983) over twenty years ago. These authors, as well as Harris and Raviv (1993), Kandel and Pearson (1995), and Morris (1995) explicitly reject the core tenet of the efficient market hypothesis that persons begin with common prior beliefs and develop heterogeneous beliefs only because they receive private signals. Instead, they stress that persons may hold divergent opinions even when all information is public, the reason being that they process this information differently. Heterogeneity in the processing of information is also a central theme of recent research in behavioral finance; Daniel, Hirshleifer, and Teoh (2002) review this literature.

To provide an empirical foundation for study of expectations, we have undertaken survey research measuring in probabilistic terms the beliefs that Americans hold about equity returns in the year ahead. Since 
the early 1990s, economists engaged in survey research have increasingly asked respondents to report probabilistic expectations of significant personal events. Manski (2004) reviews the development and current state of the literature.

We originally posed a series of questions on our Survey of Economic Expectations (SEE) in July 1999-March 2001 and later placed one of these on the Michigan Survey of Consumers beginning in June 2002. The question posed in both surveys asks respondents to state the percent chance that a diversified mutual fund will have a positive nominal return in the year ahead. The wording in the Michigan survey is as follows:

Positive NominalReturn (PNR): The next question is about investing in the stock market. Please think about the type of mutual fund known as a diversified stock fund. This type of mutual fund holds stock in many different companies engaged in a wide variety of business activities. Suppose that tomorrow someone were to invest one thousand dollars in such a mutual fund. Please think about how much money this investment would be worth one year from now. What do you think is the percent chance that this one thousand dollar investment will increase in value in the year ahead, so that it is worth more than one thousand dollars one year from now?

The SEE instrument posed this question within a sequence of questions asking for the percent chance that the mutual fund will increase or decrease in value by specified amounts. From June 2003 through August 2004, the Michigan survey contained an additional question asking for the percent chance that the mutual fund would have a positive real return.

Dominitz and Manski $(2003,2004)$ described the responses to the Michigan survey in June 2002May 2003. We reported that expectations of a positive nominal equity return varied substantially across persons and systematically with sex, age, and schooling. We also reported that individual beliefs exhibited considerable stability over time. The latter finding emerged from the longitudinal feature of the Michigan survey, which provides two interviews for most respondents, spaced six months apart. 
This paper presents a broader and deeper analysis of the Michigan and SEE data. The broadening occurs in Section 2 where we extend our earlier description of the survey responses to encompass the Michigan respondents interviewed in June 2002-August 2004 and the SEE respondents interviewed in July 1999-March 2001. The deepening occurs in Section 3, where we attempt to shed light on the processes of expectations formation underlying the survey responses.

The analysis in Section 2 strengthens the major descriptive conclusions of Dominitz and Manski $(2003,2004)$. We find that expectations of equity returns vary considerably across persons who are interviewed contemporaneously; moreover, the patterns of variation are similar within the Michigan and SEE samples. We also find that Michigan respondents who are interviewed twice tend to give similar responses at six-month intervals. Taken together, these empirical findings suggest that individuals use interpersonally variable but intrapersonally stable processes to form their expectations. We therefore propose in Section 3 that it is reasonable to think of the population as a mixture of expectations types, each forming expectations in a stable but different way.

In Section 3, we attempt to use the Michigan and SEE data to learn about the prevalence of different types. We focus on three types that are suggested by thinking in conventional and behavioral finance. One is a random-walk $(R W)$ type, who believes that equity returns are independent and identically distributed over time and who, given this belief, uses the long-run historical record of returns to predict future returns. Another is a persistence $(P)$ type, who believes that recent stock market performance will persist into the near future. The third is a mean-reversion (MR) type, who believes that recent stock market performance will be reversed in the near future.

If one examines informally the central tendency of the expectations data, one may obtain the impression that the population believes in some form of persistence. Mean expectations of equity returns were much higher at the end of the boom period when the SEE data were collected (Jul-99 to Mar-01) than during the less robust period of the Michigan data (Jun-02 to Aug-04). Moreover, both realized returns and 
expectations tended to rise during the course of the latter period. However, when we confront formally the problem of inference on the distribution of types, we find that the heterogeneity of expectations overwhelms whatever regularity is apparent in the central tendency.

Very few persons have expectations near those of the RW, P, and MR types, as we define them. It may be that other definitions of these types could improve matters to some extent. However, we do not think that any parsimonious specification of types can adequately explain the diverse expectations of the Michigan and SEE respondents. We conclude, in Section 4, that progress in understanding how people form their expectations of equity returns will require much more extensive data than we now have.

Our past and present research contributes to a small but growing literature using various types of questions to elicit expectations of equity returns and related quantities from diverse populations. The distinguishing feature of our data collection and analysis is its use of probabilistic questions to learn the beliefs of the general population of adult Americans. Manski (2004) discusses in depth the reasons why we favor probabilistic questioning rather than elicitation of point forecasts or verbal measurement of uncertainty. We think it important to learn the beliefs of the general population because Americans are increasingly being called upon to participate actively in the stock market through management of defined-contribution pension plans and, potentially, through partial privatization of Social Security.

Other work to date differs from ours in various respects. Kandel and Pearson (1995) analyzed the point predictions of financial analysts for the earnings of specific firms. Welch (2000) elicited point predictions of the equity premium from financial economists. Benartzi (2001) questioned employees about the future performance of the stocks of their own firms relative to that of the aggregate market. These and similar contributions are remote from ours.

Research by Graham and Harvey (2001) and Vissing-Jorgensen (2004) is closer in spirit to our work in some respects, but still different in others. Graham and Harvey analyzed responses to these questions posed to the Chief Financial Officers (CFOs) of certain corporations: 
a) Over the next 10 years, I expect the S\&P 500 will average a ___ $\%$ annual return

b) During the next year, I expect the S\&P to return _ $\%$

c) During the next year, there is a 1 -in-10 chance the S\&P 500 return will be higher than __ $\%$

d) During the next year, there is a 1-in-10 chance the S\&P 500 return will be lower than _ $\%$

Observe that questions (a) and (b) seek point forecasts but questions (c) and (d) are probabilistic in nature.

Vissing-Jorgensen (2004) analyzed responses to questions on equity returns administered by the UBS and Gallup firms in 1998-2002 to respondents in American households possessing at least $\$ 10,000$ in financial assets. The questions are

UBS/Gallup: "Thinking about the stock market more generally, what overall rate of return do you think the stock market will provide investors during the coming twelve months?" "And, what annual rate of return do you think the stock market will provide investors over the next ten years?"

These questions differ from those administered in SEE and the Michigan survey primarily in that they seek point predictions of equity returns rather than probabilistic expectations.

\section{Measuring Expectations}

2.1. Michigan Survey of Consumers: June 2002 - August 2004

Each month, the Michigan Survey of Consumers is completed by telephone by approximately 500 adult men and women who live in the coterminous United States. The survey has a rotating panel design, in which the majority of individuals (approximately 300) are first time respondents and the remainder (approximately 200) are persons who were first interviewed six months earlier; see Curtin (1982). 


\section{Temporal Variation in Responses}

We analyze data collected in the 27-month period June 2002-August 2004. Table 1 gives summary statistics on the distribution of responses to the positive-returns question, month by month. The table shows that expectations of a positive nominal equity return tended to rise over the sample period. The mean monthly responses were in the low 40s early on (Jun-02-Apr-03), in the upper 40s in the middle of the period (May-03-Oct-03), and in the low 50s thereafter (Nov-03-Aug-04).

Anyone familiar with the performance of the American stock market in 2002-2004 will recall that realized nominal equity returns also tended to rise during our sample period. The last column of Table 1 shows that the realized one-year return on the Standard \& Poor 500 (S\&P 500) Index was negative in every month from June 2002 through June 2003 and positive in every month from July 2003 through August 2004. This suggests that at least part of the population believed recent stock market performance would persist into the near future. We will return to this topic in Section 3.

Although responses to the positive-returns question tended to rise over the sample period, individual beliefs nevertheless exhibited considerable temporal stability. The sample contains 3885 persons who responded to question PNR twice, in interviews spaced six months apart. Of these persons, 0.184 gave exactly the same response in both interviews and 0.425 give pairs of responses that were the same or differed by no more than 10 percent.

Table 2 cross-tabulates the responses of the persons who were interviewed twice. Considered in the large, the table shows that responses on the two interviews tend to remain on the same side of the value "50 percent;" the upper right and lower left parts of the table contain relatively few persons. Among those who report less (more) than a 50 percent chance on their first interview, only $0.216(0.177)$ subsequently report more (less) than a 50 percent chance. Considered in the small, the table shows certain diagonal elements to be particularly prominent. In particular, the cells $(50,50),(71-80,71-80)$, and (0-9, 0-9) respectively contain $0.071,0.042$, and 0.037 of all respondents. 


\section{Cross-Sectional Distribution of Responses}

Table 1 shows that, each month, responses to the positive-returns question varied considerably among the persons interviewed by the Michigan survey. Table 3 aggregates over time in order to examine more closely the cross-sectional distribution of responses. This table pools the 27 monthly samples of firsttime respondents, yielding a total sample size of 8020 separate persons. In these interviews, there were 7411 responses to question PNR, giving an item response rate of 0.92 .

The top row of the table shows that the mean response was 46.4 percent and the standard deviation was 29.4. The lower rows of the table show that some of the heterogeneity in responses is systematic, in the sense that persons with different demographic attributes have different distributions of expectations. Focusing on the group means, we find that males tended to be more optimistic than females (mean 50.2 percent versus 43.2 percent) and non-Hispanic whites tended to be more optimistic than other ethnic/racial groups. Optimism about equity returns increased with schooling, from a mean response of 40.1 percent for those with no postsecondary education to 51.6 for those with a bachelor's degree. Younger persons were more optimistic than older ones, with the mean response falling from 51.0 percent for respondents under age 35 to 36.1 percent for those 65 and older; most of this decline occurred at the highest age group. Finally, we find that nonresponse was highest in the parts of the population that tend to be least optimistic. For example, 13 percent of the persons with no postsecondary education did not respond versus 3 percent of those with a bachelor's degree.

Although Table 3 shows systematic variation in expectations across groups, it also shows that population-wide heterogeneity occurs mainly within each group rather than between the groups. The withingroup standard deviation of responses to question PNR is remarkably similar across the groups, in all cases being at least 26.7 and no more than 31.7 . One might conjecture that members of groups who tend to have enough financial assets to be able to invest in equities would have reason to think about equity returns carefully and, as a consequence, would have relatively homogeneous beliefs. Such persons may think about 
equity returns carefully, but care in thought apparently does not translate into homogeneity of beliefs. Consider in particular the group of respondents with a bachelor's degrees. Their within-group standard deviation of responses is 29.2 , essentially the same as that of persons with no postsecondary schooling.

To describe how expectations vary with multiple personal attributes and over time, Table 4 presents best linear predictors under square loss of the responses to question PNR. All of the univariate patterns evident in Table 3 recur here. Moreover, the month-specific coefficients closely follow the time trends in mean expectations and S\&P 500 return realizations shown in Table 1.

\section{Expectations of Positive Real Returns}

Question PNR elicits expectations that equities will have a positive nominal return in the year ahead. In the period June 2003-August 2004, the Michigan survey posed an additional question eliciting expectations of a positive real return. The wording of this question was:

Positive Real Return (PRR): And thinking again about the one thousand dollar investment in a mutual fund, what do you think is the percent chance that this one thousand dollar investment will increase in value in the year ahead by more than prices will go up?

Comparison of the responses to questions PNR and PRR shows that, even in the low inflation environment of 2003-2004, most respondents were cognizant that the nominal return on equities exceeds the real return. Let $\Delta$ denote the difference between a person's responses to questions PNR and PRR. In the period when both questions were asked, the mean value of $\Delta$ was 9.9 percent. The $0.25,0.5$ and 0.75 quantiles of $\Delta$ were 0,5 , and 20 percent respectively. 
2.2. Survey of Economic Expectations: July 1999 - March 2001

Question PNR was posed to 1651 SEE respondents in the three waves of the survey conducted in the period July 1999-March 2001. SEE, like the Michigan survey, was conducted by telephone with a national sample of respondents; Dominitz and Manski (1997a) describe the basic features of the survey. The item nonresponse rate to the SEE administration of question PNR was 0.27 , considerably higher than the 0.07 experienced when the same question has subsequently been administered on the Michigan Survey. ${ }^{1}$ For this reason, the SEE findings should be interpreted with more caution than the Michigan ones.

Table 1 gives summary statistics on the distribution of SEE responses, wave by wave. Comparison of these results with those for the Michigan survey indicates that expectations of positive equity returns in the period July 1999-March 2001 tended to be sharply higher than in the period June 2002-August 2004. Whereas the mean responses ranged from 66.1 to 70.8 percent in the three waves of SEE, they ranged from 39.3 to 53.7 percent in the 27 months of the Michigan survey. This large temporal difference in expectations accords with the conventional view of the turn of the century as the tail end of a long stock-market boom period that was expected to persist at the time, but that eventually did run its course.

Table 3 describes the cross-sectional distribution of the responses. The SEE respondents exhibited less of the systematic sex variation in expectations that we found among the Michigan respondents; the mean responses of males and females were 68.6 and 67.3 percent respectively. In other respects, the SEE variation in expectations across demographic groups was similar to the Michigan sample. Non-Hispanic whites tended to be more optimistic than non-Hispanic blacks (mean 68.8 versus 64.7). Optimism about equity returns increased with schooling, from a mean of 59.1 for those with no postsecondary education to 70.5 for those

${ }^{1}$ The variation in response rates is due in part to a skip-sequencing feature of the SEE questionnaire. Respondents were first asked to state the minimum and maximum values they believe the mutual fund investment may have a year after the interview. Many respondents did not answer these questions and, hence, were not asked question PNR. The Michigan survey did not contain the preliminary questions asking for minimum and maximum values. 
with a bachelor's degree. Persons under age 65 tended to be significantly more optimistic about equity returns than did persons of age 65 and above. As in the Michigan sample, SEE nonresponse was highest in the parts of the population that tend to be least optimistic; for example, 48 percent of those with no postsecondary education did not respond versus 18 percent of those with a bachelor's degree.

To describe how expectations vary with multiple personal attributes and over time, Table 4 presents best linear predictors under square loss. The univariate patterns in Table 3 recur and the wave-specific coefficients follow the time trend in mean expectations shown in Table 1. Moreover, the variation of expectations with personal attributes resembles the variation in the Michigan sample.

\section{Fitting Subjective Distributions}

The positive-returns question was one of a sequence of SEE questions asking for the percent chance that a mutual fund would be worth more than several specified thresholds in the year ahead. The questions in the sequence had this form: ${ }^{2}$

What do you think is the percent chance that, one year from now, this investment would be worth over \$Y?

The responses to this sequence of questions can be used to fit person-specific subjective distributions

2 Four thresholds $\mathrm{Y}$ were determined by the respondent's answer to preliminary questions asking for the lowest and highest possible future values of the investment. The midpoint of the reported lowest and highest values was used to determine the thresholds according to this algorithm:

\begin{tabular}{|c|c|c|c|c|}
\hline Midpoint & Y1 & Y2 & Y3 & Y4 \\
\hline 0 to 899 & 500 & 900 & 1000 & 1100 \\
900 to 999 & 800 & 900 & 1000 & 1100 \\
1000 to 1099 & 900 & 1000 & 1100 & 1200 \\
1100 to 1299 & 1000 & 1100 & 1200 & 1500 \\
1300 or more & 1000 & 1200 & 1500 & 2000 \\
\hline
\end{tabular}

Observe that $\$ 1000$ is always one of the four thresholds; hence, all persons were asked question PNR. 
for equity returns in the year ahead. To fit these distributions, we assume that person $\mathrm{j}$ interviewed at time t has a normal subjective distribution $\mathrm{N}\left(\mu_{\mathrm{jt}}, \sigma_{\mathrm{jt}}{ }^{2}\right)$ and we use a least-squares criterion to find the value of $\left(\mu_{\mathrm{j} t}\right.$, $\left.\sigma_{\mathrm{jt}}\right)$ that best fits the person's responses. We have previously used this approach to fit person-specific subjective income distributions (Dominitz and Manski, 1997b), except that we assumed subjective distributions of income are log-normal rather than normal.

Table 5 describes the cross-sectional distribution of the values of $(\mu, \sigma)$ fitted for the 986 respondents who answered all of the questions and whose responses yielded a unique fitted value for $(\mu, \sigma){ }^{3}$ When examining the findings, it is helpful to keep in mind the historical mean and standard deviation of one-year equity returns in the United States. According to Mehra and Prescott (2003), the historical mean real return on equities has been about 0.07 and the standard deviation has been near 0.20 . Moreover, the inflation rate has remained low and non-volatile in recent years, generally being between 0.02 and 0.03 .

The cross-sectional distributions of $(\mu, \sigma)$ are better summarized through the quantiles shown in the table than by the means and standard deviations, which are heavily influenced by a few very large outliers. The $(0.25,0.50,0.75)$-quantiles of $\mu$ were $(0.04,0.20,0.50)$ respectively. This indicates that most SEE respondents expected equity returns in the year ahead to be considerably higher than the historical average return. The $(0.25,0.50,0.75)$-quantiles of $\sigma$ were $(0.19,0.39,0.74)$. This indicates that most SEE respondents perceived equity returns in the year ahead to be substantially more volatile than one-year returns have been in the past.

\footnotetext{
${ }^{3} 1189$ persons answered all four questions. For various reasons, we could not fit a subjective distribution to the responses of 203 of these persons. For example, a distribution cannot be fit if the person gives the same response to all four questions.
} 


\section{$\underline{\text { 3. Interpreting the Measured Expectations }}$}

The Michigan and SEE data show that expectations of equity returns vary considerably across persons who are interviewed contemporaneously (see Table 1). We have also found that Michigan respondents who are interviewed twice tend to give similar responses at six-month intervals (see Table 2). In conjunction, these empirical findings suggest that individuals use interpersonally variable but intrapersonally stable processes to form their expectations. It therefore seems reasonable to think of the population as a mixture of expectations types, each forming expectations in a stable but different way.

In this section, we use the Michigan and SEE data to learn about the prevalence of different types. Section 3.1 defines some types that are suggested by thinking in conventional and behavioral finance. Section 3.2 explains how we approach the problem of inference on the distribution of types in the population. Section 3.3 presents empirical findings.

\subsection{Expectations Types}

\section{General Considerations}

There are many reasons why persons may differ in their responses to the Michigan and SEE questions. First, persons may differ in the way they interpret the mutual fund described in the questions. The questions characterize a diversified stock fund as one that "holds stock in many different companies engaged in a wide variety of business activities" and ask respondents to "suppose that tomorrow someone were to invest one thousand dollars in such a mutual fund." This wording aims to be informative, but we cannot be certain that it means the same thing to all respondents. For example, it may be that respondents who currently hold mutual funds report expectations for the performance of their own investments.

Second, persons may differ in their expectations because they possess private information about the 
operation of the stock market. The idea that persons possess private information has been central to much research in economic theory and seems credible in many empirical settings. However, we doubt that many people have meaningful private information relevant to prediction of mutual fund returns. Persons may vary in the attention that they give to the information that is publicly available, but that is another matter.

Third, persons may differ in the way that they use available information to form expectations of future equity returns. This idea has been central to the body of research on asset markets, cited in the Introduction, which stresses that persons may hold divergent opinions even when all information is public. We think that differences in the way people use public information must underlie much of the variation in expectations that we observe.

Three Specific Types

Conventional and behavioral finance suggest a number of ways that persons may use public information to form expectations for future returns. For specificity, we focus on types that have normal subjective distributions for equity returns and use the time series of past values of the S\&P 500 index to form the mean and variance of their subjective distributions. Within this setting, we consider three ways in which persons may use the S\&P time series, as follows:

Random Walk $(R W)$ Type: A person subscribing to a random-walk theory of the stock market might use the long-run historical record of equity returns to predict future returns. As mentioned earlier, the historical mean real return on equities has been 0.07 and the standard deviation has been near 0.20 . The inflation rate has remained low and non-volatile in recent years, generally being between 0.02 and 0.03 . Based on this evidence, we take the subjective distribution of one-year-ahead returns of a random-walk type to be $N\left(\mathrm{~m}, \mathrm{~s}^{2}\right)$, 
where $\mathrm{m}=0.095$ and $\mathrm{s}=0.18$. The implied chance of a positive nominal return is 70.1 percent. $^{4}$

Persistence (P) Type: A common conjecture in behavioral finance has been that persons believe recent stock market performance will persist into the near future. The descriptive empirical findings of Section 2 give credence to this conjecture. We found that expectations of equity returns tended to be much higher at the end of the boom period when the SEE data were collected (Jul-99 to Mar-01) than during the less robust period of the Michigan data (Jun-02 to Aug-04). Moreover, both realized returns and expectations rose during the course of the latter period. These patterns suggest that at least part of the population believe in some form of persistence.

Let $\mathrm{x}_{\mathrm{t}}$ be the realized one-year equity return for the year ending at date $\mathrm{t}$; that is, $\mathrm{x}_{\mathrm{t}}$ is the value at $\mathrm{t}$ of a dollar invested a year earlier. For specificity, we measure $\mathrm{x}_{\mathrm{t}}$ by the realized return to the S\&P 500 index during the past year, given in the last column of Table 1 . We take $\mathrm{x}_{\mathrm{t}}$ to be the subjective mean one-yearahead return of a persistence type.

The idea that recent experience will persist into the near future also suggests that the recent volatility of equity returns will persist. We take the subjective standard deviation of a persistence type to be the realized standard deviation of returns in the past five years, denoted $\mathrm{w}_{\mathrm{t}}$. Thus, the subjective distribution of one-year-ahead returns of a persistence type is $N\left(\mathrm{x}_{\mathrm{t}}, \mathrm{w}_{\mathrm{t}}^{2}\right)$.

Mean Reversion (MR) Type: Another common conjecture in behavioral finance has been that persons believe recent stock market performance will be reversed in the near future. The idea is that if equity returns have

\footnotetext{
${ }^{4}$ When considering responses to the positive-returns question, one may alternatively think of a random-walk type as someone who observes the historical frequency with which the one-year nominal return on equities was positive and uses this as his subjective probability that the return will be positive in the year ahead. This nonparametric approach avoids the normality assumption made in our definition. Inspection of the S \& $\mathrm{P}$ 500 time series for each calendar year of the 15 year period 1990-2004 reveals that the index rose in 10 out of the 15 years, or 66.7 percent of the time.
} 
recently been high relative to the historical average, then future returns will tend to be correspondingly low. To formalize this, we take $2 \mathrm{~m}-\mathrm{x}_{\mathrm{t}}$ to be the subjective mean one-year-ahead return of a mean reversion type. The idea of mean reversion does not suggest a particular way to form expectations for future volatility. We take the subjective standard deviation of a mean-reversion type to be the historical standard deviation. Thus, the subjective distribution of one-year-ahead returns of a mean reversion type is $N\left(2 \mathrm{~m}-\mathrm{x}_{\mathrm{t}}, \mathrm{s}^{2}\right)$.

\section{Other Types}

The types defined above give specific form to broad ideas about expectations formation evident in finance research. There are, of course, other specific ways to express these broad ideas. We have already mentioned an alternative version of the random-walk type, who uses historical data nonparametrically rather than through the filter of a normal distribution (see footnote 3). When defining a persistence or meanreversion type, one might use something other than last year's return on the S\&P 500 Index to measure recent stock market performance. One might also change the specifications of subjective volatility that we have made when defining these types. Varying the definitions of types in these ways would retain their qualitative features but would yield quantitatively different subjective distributions for equity returns and, hence, would affect the empirical findings that we report in Section 3.3.

One might also contemplate types that combine the ideas of a random walk, persistence, and mean reversion. For example, Barberis, Shleifer, and Vishny (1998) define a type who believes that the stock market alternates between regimes of persistence and mean reversion. As new information arrives, this type uses Bayes rule to update his beliefs about the nature of the current regime.

Another direction for definition of other types is to drop the assumption that persons use only past market performance to form their expectations. An enormous variety of economic, political, and other news becomes publicly available each day. There are many ways in which someone might think this news relevant to prediction of future equity returns. 


\subsection{The Inferential Problem}

This section considers what the Michigan, SEE, or similar data can reveal about the prevalence of different types in the population. We treat the inferential problem in generality, and so do not mention specific types by name.

Our approach to inference is simple. Considering any given type, we ask whether the expectations responses provided by a person are consistent with those that would be provided by this type. If the responses are not consistent, the person is not of this type. If they are consistent, then the person may be of this type. Thus, the data provide an upper bound on the prevalence of the type in the population. We place no restrictions on the space of feasible types. Hence, we cannot provide a lower bound on the prevalence of any type.

Our approach to inference presumes that type is a temporally stable trait. Hence, a person may be of a given type only if all his responses are consistent with this type. One might alternatively think of a type as an unstable trait that can vary as a person responds to different questions. The latter conceptualization of types is much weaker than what we have in mind and seems to us much less useful.

Our approach differs from other work that attempts to infer a distribution of latent types in a population. El-Gamal and Grether (1995) use experimental data to infer the distribution of belief-updating rules used by subjects who are given new information. Houser, Keane, and McCabe (2004) use experimental data to infer the distribution of decision rules used by subjects facing dynamic choice problems. Although these articles differ from one another, they both maintain assumptions about the space of feasible types that are strong enough to identify the distribution of types in the population of interest.

\section{Upper Bound on the Prevalence of a Specified Type}

To begin, let $\mathrm{k}$ denote a specified type. At date $\mathrm{t}$, let $\mathrm{P}_{\mathrm{kt}}$ denote the subjective probability distribution 
that someone of type $k$ places on the nominal equity return $r$ in the year ahead. Let $p_{k t y} \equiv P_{k t}(r>y)$.

Suppose that person $\mathrm{j}$ is asked at date $\mathrm{t}$ to state his subjective probability that $\mathrm{r}$ will exceed $\mathrm{y}$ and responds with the value $\mathrm{q}_{\mathrm{jty}}$. Suppose, for the moment, that $\mathrm{q}_{\mathrm{jty}}$ precisely expresses the person's subjective probability. Then comparison of $\mathrm{q}_{\mathrm{jty}}$ with $\mathrm{p}_{\mathrm{kty}}$ reveals whether person $\mathrm{j}$ may be of type $\mathrm{k}$. Person $\mathrm{j}$ is not of type $\mathrm{k}$ if $\mathrm{q}_{\mathrm{jty}} \neq \mathrm{p}_{\mathrm{kty}}$ and may be of type $\mathrm{k}$ if $\mathrm{q}_{\mathrm{jty}}=\mathrm{p}_{\mathrm{kty}}$. Observe that the equality $\mathrm{q}_{\mathrm{jty}}=\mathrm{p}_{\mathrm{kty}}$ is a necessary condition for $\mathrm{j}$ to be of type $\mathrm{k}$, but not a sufficient one. There may exist other types with subjective probability $p_{\text {kty }}$.

We think it too strong to suppose that responses to survey questions measure subjective probabilities precisely. Our experience in many studies measuring expectations has been that persons asked "percent chance" questions tend to give precise answers only at the extremes, where they may respond 1, 2, 98, or 99 percent. Otherwise, persons tend to round their responses to the nearest 5 or 10 , with further rounding in the vicinity of 50. Such rounding is evident in Table 6, which gives the frequency distributions of Michigan and SEE responses to question PNR.

The pervasiveness of rounding suggests that we should interpret $\mathrm{q}_{\mathrm{jty}}$ as providing an interval rather than point measure of person j's subjective probability, the interval depending on the response given. Let $\left[\mathrm{q}_{0 \mathrm{jty}}, \mathrm{q}_{1 \mathrm{jty}}\right]$ denote the interval induced by observation of $\mathrm{q}_{\mathrm{jty}}$. Then comparison of $\left[\mathrm{q}_{\mathrm{ojty}}, \mathrm{q}_{1 \mathrm{jty}}\right]$ with $\mathrm{p}_{\mathrm{kty}}$ reveals whether person $\mathrm{j}$ may be of type $\mathrm{k}$. Person $\mathrm{j}$ is not of type $\mathrm{k}$ if $\mathrm{p}_{\mathrm{kty}} \notin\left[\mathrm{q}_{\mathrm{ojty}}, \mathrm{q}_{1 \mathrm{jty}}\right]$ for any of the questions that person $\mathrm{j}$ is asked. Person $\mathrm{j}$ may be of type $\mathrm{k}$ if $\mathrm{p}_{\mathrm{kty}} \in\left[\mathrm{q}_{0 \mathrm{jty}}, \mathrm{q}_{\mathrm{ljty}}\right]$ for all of the questions asked.

It remains to define the intervals $\left[\mathrm{q}_{0 \mathrm{jty}}, \mathrm{q}_{1 \mathrm{jty}}\right]$. We have no direct knowledge of the amount of rounding performed by any respondent. However, we think it reasonable to assume that persons reporting a value of $\mathrm{q}_{\mathrm{jty}}$ that ends in a 0 other than 50 are rounding no more than to the nearest 10 , those reporting a value ending in a 5 are rounding to no more than the nearest 5 , and those reporting other values are rounding to no more than the nearest 1 . Implementing these assumptions and permitting further rounding when the response is 
50, we use these intervals in our empirical analysis: ${ }^{5}$

$$
\begin{aligned}
& \mathrm{q}_{\mathrm{jty}}=0 \Rightarrow\left[\mathrm{q}_{0 \mathrm{jty}}, \mathrm{q}_{1 \mathrm{jty}}\right]=[0,5] ; \\
& \mathrm{q}_{\mathrm{jty}}=50 \Rightarrow\left[\mathrm{q}_{0 \mathrm{jty}}, \mathrm{q}_{1 \mathrm{jty}}\right]=[40,60] ; \\
& \mathrm{q}_{\mathrm{jty}}=100 \Rightarrow\left[\mathrm{q}_{0 \mathrm{jty}}, \mathrm{q}_{1 \mathrm{jty}}\right]=[95,100] ; \\
& \mathrm{q}_{\mathrm{jty}} \text { ends in a } 0 \text { but } \mathrm{q}_{\mathrm{jty}} \neq 0,50,100 \Rightarrow\left[\mathrm{q}_{0 \mathrm{jty}}, \mathrm{q}_{1 \mathrm{jty}}\right]=\left[\mathrm{q}_{\mathrm{jty}}-5, \mathrm{q}_{\mathrm{jty}}+5\right] ; \\
& \mathrm{q}_{\mathrm{jty}} \text { ends in a } 5 \Rightarrow\left[\mathrm{q}_{0 \mathrm{jty}}, \mathrm{q}_{1 \mathrm{jty}}\right]=\left[\mathrm{q}_{\mathrm{jty}}-3, \mathrm{q}_{\mathrm{jty}}+3\right] ; \\
& \text { otherwise, }\left[\mathrm{q}_{0 \mathrm{jty}}, \mathrm{q}_{1 \mathrm{jty}}\right]=\left[\mathrm{q}_{\mathrm{jty}}-1, \mathrm{q}_{\mathrm{jty}}+1\right] .
\end{aligned}
$$

Whether the intervals $\left[\mathrm{q}_{0 \mathrm{jty}}, \mathrm{q}_{1 \mathrm{jty}}\right]$ are defined as above or otherwise, the Michigan and SEE responses place an upper bound on the prevalence of type $\mathrm{k}$ in the population. The data per se do not place a lower bound on the prevalence of this type. The reason is that multiple types may give the same responses to the questions posed.

\section{Upper Bound on the Prevalence of a Specified Set of Types}

The foregoing discussion has considered inference on the prevalence of a specified type in the population. An obvious generalization is inference on the prevalence of a specified set of types. Let $\mathrm{K}$ denote these types. Once again, suppose that person $\mathrm{j}$ is asked at date $\mathrm{t}$ to state his subjective probability that $r$ will exceed $y$. Person $j$ does not have a type in set $K$ if $\mathrm{p}_{\text {hty }} \notin\left[\mathrm{q}_{0 \mathrm{jty}}, \mathrm{q}_{1 \mathrm{jty}}\right]$ for all $\mathrm{h} \in \mathrm{K}$. This person may have

\footnotetext{
${ }^{5}$ Although we think that these intervals are reasonable, we cannot be certain that they accurately describe the rounding performed by all respondents. Perhaps most questionable is the $[40,60]$ interval placed around responses of 50 percent. Bruine de Bruin et al. (2000) conjecture that some persons answer 50 percent when they are unable to make any reasoned probability assessment but nevertheless want to respond to the interviewer. If so, the responses of 50 percent that we observe are some mixture of rounded subjective probabilities and expressions of what Bruine de Bruin et al. call epistemic uncertainty.

Our data for Michigan respondents who are interviewed twice enable us to conclude that at most onethird of the persons who state 50 percent are expressing epistemic uncertainty. Table 2 shows that 0.23 of all persons respond 50 percent on their first interview and 0.22 respond 50 percent on their second interview. However, only 0.07 of all persons respond 50 percent on both interviews. Hence, we conclude that at most 0.07 of all persons use the value 50 percent to express epistemic uncertainty.
} 
a type in set $K$ if $p_{\text {hty }} \in\left[\mathrm{q}_{0 \mathrm{jty}}, \mathrm{q}_{1 \mathrm{jty}}\right]$ for some $\mathrm{h} \in \mathrm{K}$. Hence, the Michigan and SEE responses place an upper bound on the prevalence of the set $\mathrm{K}$ in the population.

Near Types

For practical purposes, it may be overly stringent to ask whether a person forms expectations in exactly the manner of a specified type. It may be more interesting to inquire whether someone is near type k, given a sensible definition of "near." In our empirical analysis, we define someone to be near type k if his subjective distribution of returns is uniformly within .05 of the distribution held by type $\mathrm{k}$. Thus, we judge person to be not near type $\mathrm{k}$ if $\left[\mathrm{p}_{\mathrm{kty}}-.05, \mathrm{p}_{\mathrm{kty}}+.05\right] \cap\left[\mathrm{q}_{0 \mathrm{jty}}, \mathrm{q}_{\mathrm{ljty}}\right]$ is null for any of the questions asked and possibly near type $\mathrm{k}$ if $\left[\mathrm{p}_{\mathrm{kty}}-.05, \mathrm{p}_{\mathrm{kty}}+.05\right] \cap\left[\mathrm{q}_{0 \mathrm{jty}}, \mathrm{q}_{1 \mathrm{jty}}\right]$ is non-null for all of the questions asked.

\subsection{Findings}

\section{Michigan Data}

Table 7 shows the responses to the positive-returns question that the random-walk, persistence, and mean-reversion types would give in each month for which we have Michigan data. The three types have substantially different expectations in most months. Exceptions are Jul-03, Aug-03, and Aug-04, when all three would give essentially the same response.

Table 8 reports upper bounds on the prevalence of the three types among the Michigan respondents. The table separately reports findings for persons with one and two interviews, and also for the full sample that pools all respondents. The bounds labeled "Exact" uses the exact type-specific responses to question PNR, shown in Table 7, to judge whether a respondent is possibly of each type. Those labeled "Near" use a .05 band around these responses, as explained at the end of Section 3.2. We focus our discussion on the Near findings because we think the Exact criterion to be overly stringent for practical purposes. 
Persons with One Interview: Table 8 shows that, among persons who are interviewed once, at most 0.180 are near type RW, at most 0.196 are near type $\mathrm{P}$, and at most 0.142 are near type MR. At most 0.434 are near the set of three types. There are several ways to view these findings, which emphasize different features of the empirical evidence.

Someone who favors a particular hypothesis about expectations formation, say persistence, might emphasize that a sizeable fraction of the population ( 0.196 in the case of persistence) potentially form their beliefs in this manner. Someone who does not favor a particular hypothesis but who seeks a parsimonious interpretation of observed expectations of equity returns might emphasize that a model positing only types near RW, P, and MR suffices to "explain" the expectations held by close to half $(0.434)$ of the population. On the other hand, someone who thinks that persons vary widely in the way they form their expectations might emphasize that a model supposing that all persons are near these three types cannot explain the beliefs of over half the population.

Persons with Two Interviews: Consistency with the expectations of a particular type on two interviews is more difficult to achieve than consistency on one interview. Hence, we anticipated that the upper bounds for persons interviewed twice would lie below those for persons interviewed once. ${ }^{6}$ The open question was how much lower they would be.

Among persons who are interviewed twice, at most 0.076 are near type $\mathrm{RW}$, at most 0.045 are near type $\mathrm{P}$, and at most 0.028 are near type MR. At most 0.144 are near one of the three types. These findings are much less favorable to the first two perspectives described above. Someone favoring the persistence

\footnotetext{
${ }^{6}$ Nesting of the bounds is necessary as a matter of logic if one consider only persons who are interviewed twice and computes two sets of bounds for these persons, one using their responses in a single interview and the other using both responses. Nesting is not logically necessary in our analysis because the persons who are interviewed twice are distinct from those who are interviewed once. The former are persons who agreed to be interviewed twice. The latter are a mixture of persons who refused to be interviewed a second time and ones whom we observe only on one of their two interviews.
} 
hypothesis can at most assert that 0.045 of the population form beliefs in a manner similar to type $\mathrm{P}$. Someone seeking a parsimonious model can explain the expectations of only 0.144 of the population through types near RW, P, and MR.

Our findings for persons with two interviews show that persons near types RW, P, and MR cannot be very prevalent in the population. However, the evidence in Table 8 leaves open the possibility that persons form expectations in other ways that express the broad ideas of a random walk, persistence, and/or mean reversion. To investigate this, one may define other specific types that embody these broad ideas and perform analysis analogous to what we have carried out here.

\section{SEE Data}

The SEE questionnaire asked persons to answer four questions; hence, consistency with a given type requires that all four responses be near those that would be given by this type. Among the 1189 persons who answered all four questions, we find that at most 0.021 are near type $\mathrm{RW}$, at most 0.008 are near type $\mathrm{P}$, and at most 0.014 are near type MR. At most 0.038 are near one of the three types. Thus, our conclusions from analysis of the Michigan respondents with two interviews are amplified in the SEE data.

\section{Conclusion}

The empirical analysis of Section 3.3 showed that few Michigan and SEE respondents have expectations of equity returns near those of the random-walk, persistence, and mean-reversion types, as we have defined them. It may be that more can be done to explain the observed expectations by adopting other formal definitions of these types, by loosening the criterion we use to define near types, or by investigating the prevalence of some of the other types mentioned in Section 3.1. Nevertheless, we do not think that any 
parsimonious specification of types can adequately explain the diverse expectations that we observe. The descriptive analysis of Section 2 made plain that Americans vary enormously in the expectations that they hold for equity returns. Heterogeneity across persons is the overwhelming message of Tables 1 through 6 , each of which demonstrates the phenomenon in its own way.

Yet interpersonal heterogeneity in expectations does not imply intrapersonal instability. Recall that, of the Michigan respondents who were interviewed twice, 0.184 gave exactly the same response in both interviews and 0.425 gave pairs of responses that were the same or differed by no more than 10 percent. This suggests that persons tend to use temporally stable processes to form their expectations. The large open question is why these processes vary so much across persons.

We think that progress in understanding how people form expectations of equity returns will require much more extensive data than we now have. As a start, it would be helpful to combine the best elements of the SEE and Michigan surveys. SEE yielded data that enable estimation of a complete subjective distribution for each person, but had no longitudinal aspect. The Michigan survey has a limited longitudinal aspect, but only asks for expectations of positive equity returns. A potentially useful longitudinal implementation of SEE-type questions has begun recently in the Health and Retirement Study (HRS). However, the HRS is fielded only every two years and, with occasional spousal exceptions, only interviews persons over age 50 .

We think that even rich longitudinal data measuring expectations in detail will not suffice to understand expectations formation fully. Considering the general problem, without specific reference to equity expectations, Manski (2004) argues that understanding expectations formation will also require intensive probing of persons to learn how they perceive their environments and how they process such new information as they may receive. In the present case, it seems particularly important to determine what people know about historical equity returns and how they use this information to form their expectations for future returns. Large-scale population surveys such as the Michigan Survey or SEE are not amenable to 
investigations of this type - the time available to query respondents is too limited and the standardized question-response format of interviews is too confining. To learn how people process information and form expectations, economists may need to engage small samples of respondents in lengthy interviews.

It also is important to learn how expectations of equity returns affect the decisions that people make regarding asset holdings, savings, and so on. The Michigan Survey and SEE do not ask respondents for asset or saving data and so cannot be used to address this question. The HRS does provide such data and, hence, is a potentially valuable resource for future research. 


\section{$\underline{\text { References }}$}

Barberis, N., A. Shleifer, and R. Vishny (1998), “A Model of Investor Sentiment,” Journal of Financial Economics, 49, 307-343.

Benartzi, S. (2001), "Excessive Extrapolation and the Allocation of 401(k) Accounts to Company Stock?" Journal of Finance, 56, 1747-1764.

Bruine de Bruin, W., B. Fischhoff, B. Halpern-Felsher, and S. Millstein (2000), "Expressing Epistemic Uncertainty: It's a Fifty-Fifty Chance," Organizational Behavior and Human Decision Processes, 81, 115131.

Curtin, R. (1982), "Indicators of Consumer Behavior: The University of Michigan Surveys of Consumers," Public Opinion Quarterly, 46, 340-352.

Daniel, K., D. Hirshleifer, and S. Teoh, "Investor Psychology in Capital Markets: Evidence and Policy Implications," Journal of Monetary Economics, 49, 139-209.

Dominitz, J. and C. Manski (1997a), "Perceptions of Economic Insecurity: Evidence from the Survey of Economic Expectations," Public Opinion Quarterly, 61, 261-287.

Dominitz, J. and C. Manski (1997b), "Using Expectations Data to Study Subjective Income Expectations," Journal of the American Statistical Association, 92, 855-867.

Dominitz, J. and C. Manski (2003), "How Should We Measure Consumer Confidence (Sentiment)? Evidence from the Michigan Survey of Consumers," National Bureau of Economic Research Working Paper 9926.

Dominitz, J. and C. Manski (2004), "How Should We Measure Consumer Confidence?” Journal of Economic Perspectives, 18(2), 51-66.

El-Gamal, M. and D. Grether, "Uncovering Behavioral Strategies: Are People Bayesian?” Journal of the American Statistical Association, 90, 1137-1145.

Fama, E. (1970), “Efficient Capital Markets: A Review of Theory and Empirical Work," Journal of Finance, $25,383-417$.

Graham, J. and C. Harvey (2001), "Expectations of Equity Risk Premia, Volatility and Assymetry from a Corporate Finance Perspective," NBER Working Paper 8678, National Bureau of Economic Research, Cambridge, MA.

Harris, M. and A. Raviv (1993), "Differences of Opinion Make a Horse Race," Review of Financial Studies," $6,473-506$.

Houser, D., M. Keane, and K. McCabe (2004), "Behavior in a Dynamic Decision Problem: An Analysis of Experimental Evidence Using a Bayesian Type Classification Algorithm," Econometrica, 72, 781-822. 
Kandel, E. and N. Pearson (1995), "Differential Interpretation of Public Signals and Trade in Speculative Markets," Journal of Political Economy, 103, 831-872.

Keynes, J. M. (1937), “The General Theory of Employment,” Quarterly Journal of Economics, 51, 209-223.

Lintner, J. (1965), "The Valuation of Risk Assets and the Selection of Risky Investments in Stock Portfolios and Capital Budgets," Review of Economics and Statistics, 47, 13-37.

Lintner, J. (1969), “The Aggregation of Investors' Diverse Judgements and Preferences in Purely Competitive Markets," Journal of Financial and Quantitative Analysis, 4, 347-400.

Manski, C. (2004), "Measuring Expectations," Econometrica, 72, 1329-1376.

Mayshar, J. (1983), “On Divergence of Opinion and Imperfections in Capital Markets," American Economic Review, 73, 114-128.

Mehra, R. and E. Prescott (2003), "The Equity Premium in Retrospect," in, G. Constantinides, M. Harris, and R. Stulz (editors), Handbook of the Economics of Finance, Amsterdam: Elsevier.

Miller, E. (1977), “Risk, Uncertainty, and Divergence of Opinion,” Journal of Finance, 32, 1151-1168.

Morris, S. (1995), The Common Prior Assumption in Economic Theory," Economics and Philosophy, 11, 227-253.

Sharpe, W. (1964), "Capital Asset Prices: A Theory of Market Equilibrium under Conditions of Risk," Journal of Finance, 19, 452-442.

Sharpe, W. (1970), Portfolio Theory and Capital Markets, New York: McGraw-Hill.

Vissing-Jorgensen, A. (2004), "Perspectives on Behavioral Finance: Does 'Irrationality'Disappear with Wealth? Evidence from Expectations and Actions," NBER Macro Annual 2003, Cambridge, MA: MIT Press.

Welch, I. (2000), "Views of Financial economists on the Equity premium and On Professional Controversies," Journal of Business, 73, 501-37.

Williams, J. (1938), The Theory of Investment Value, Cambridge, MA: Harvard University Press. 
Table 1: Expectations of Positive Nominal Equity Return (by month)

\begin{tabular}{|c|c|c|c|c|c|c|c|c|}
\hline \multirow[t]{2}{*}{ month } & \multicolumn{2}{|c|}{ sample size $^{\mathrm{a}}$} & \multirow[t]{2}{*}{ mean } & \multirow[t]{2}{*}{ std dev } & \multicolumn{3}{|c|}{ quantile } & \multirow{2}{*}{$\begin{array}{c}\mathrm{S} \& \mathrm{P} 500 \\
\text { return }\end{array}$} \\
\hline & $\mathrm{N}$ & NR & & & .25 & .50 & .75 & \\
\hline SEE Data & & & & & & & & \\
\hline Jul-99-Nov-99 & 406 & $(141)$ & 67.5 & 28.2 & 50 & 75 & 90 & .38 \\
\hline Feb-00-May 00 & 336 & (129) & 71.0 & 26.7 & 50 & 75 & 95 & .17 \\
\hline Sep-00-Mar-01 & 470 & (169) & 66.3 & 27.3 & 50 & 75 & 90 & .05 \\
\hline Michigan Data & & & & & & & & \\
\hline Jun-02 & 448 & $(53)$ & 45.3 & 27.8 & 20 & 50 & 70 & -.19 \\
\hline Jul-02 & 459 & (42) & 41.0 & 27.8 & 20 & 50 & 60 & -.25 \\
\hline Aug-02 & 460 & (40) & 41.0 & 27.8 & 20 & 40 & 60 & -.19 \\
\hline Sep-02 & 469 & (32) & 39.6 & 28.8 & 10 & 40 & 60 & -.22 \\
\hline Oct- 02 & 458 & (44) & 39.3 & 25.9 & 20 & 42.5 & 50 & -.16 \\
\hline Nov-02 & 465 & (39) & 44.5 & 29.6 & 20 & 50 & 70 & -.18 \\
\hline Dec-02 & 464 & (36) & 43.3 & 29.0 & 20 & 50 & 60 & -.23 \\
\hline Jan-03 & 467 & (34) & 42.3 & 28.8 & 20 & 50 & 60 & -.24 \\
\hline Feb-03 & 468 & (33) & 40.8 & 28.1 & 20 & 40 & 60 & -.24 \\
\hline Mar-03 & 482 & (22) & 39.8 & 28.5 & 15 & 40 & 60 & -.26 \\
\hline Apr-03 & 460 & (40) & 41.5 & 29.5 & 19 & 40 & 65 & -.15 \\
\hline May-03 & 469 & (31) & 45.0 & 29.7 & 20 & 50 & 70 & -.10 \\
\hline Jun-03 & 452 & (48) & 47.7 & 29.2 & 20 & 50 & 70 & -.02 \\
\hline Jul-03 & 466 & (36) & 45.8 & 28.8 & 20 & 50 & 70 & .09 \\
\hline Aug-03 & 460 & (41) & 41.0 & 30.5 & 20 & 50 & 75 & .10 \\
\hline Sep-03 & 461 & (39) & 48.6 & 28.9 & 20 & 50 & 75 & .22 \\
\hline Oct-03 & 464 & (36) & 47.7 & 30.3 & 20 & 50 & 75 & .19 \\
\hline Nov-03 & 469 & (36) & 51.2 & 29.4 & 20 & 50 & 80 & .13 \\
\hline Dec-03 & 479 & (21) & 50.7 & 29.8 & 25 & 50 & 75 & .26 \\
\hline Jan-04 & 484 & (25) & 52.9 & 29.4 & 25 & 50 & 80 & .32 \\
\hline Feb-04 & 464 & (36) & 53.2 & 29.2 & 30 & 50 & 80 & .36 \\
\hline Mar-04 & 467 & (34) & 53.7 & 29.5 & 25 & 50 & 80 & .33 \\
\hline Apr-04 & 478 & (22) & 50.3 & 29.7 & 25 & 50 & 75 & .21 \\
\hline May-04 & 470 & (30) & 52.5 & 28.6 & 25 & 50 & 78 & .16 \\
\hline Jun-04 & 492 & (22) & 52.0 & 29.2 & 25 & 50 & 80 & .17 \\
\hline Jul-04 & 473 & (36) & 50.6 & 28.7 & 25 & 50 & 75 & .11 \\
\hline Aug-04 & 464 & (38) & 53.3 & 28.0 & 30 & 50 & 75 & .10 \\
\hline
\end{tabular}

${ }^{a} \mathrm{~N}=$ frequency of response to question PNR; NR = frequency of non-response

${ }^{\mathrm{b}}$ In SEE wave Jul-99-Nov-99, the realized one-year S\&P 500 return is the change in the index from September 1998 to August 1999. In Michigan month Jun-02, the return is the change in the index from July 2001 to June 2002. We compute the index for each month as the average closing value of the index across the days of the month. Returns are computed correspondingly in other waves and months. 
Table 2: Question PNR Responses for Michigan Respondents with Two Interviews $(\mathrm{N}=3885)$

\begin{tabular}{c|ccccccccccc|c} 
first & \multicolumn{10}{|c|}{ second interview } & \multirow{1}{*}{ a } \\
interview & $0-9$ & $10-19$ & $20-29$ & $30-39$ & $40-49$ & 50 & $51-60$ & $61-70$ & $71-80$ & $81-90$ & $91-100$ & all \\
\hline $0-9$ & 0.037 & 0.015 & 0.015 & 0.005 & 0.004 & 0.020 & 0.003 & 0.002 & 0.010 & 0.003 & 0.006 & 0.120 \\
$10-19$ & 0.014 & 0.014 & 0.016 & 0.006 & 0.002 & 0.017 & 0.004 & 0.003 & 0.005 & 0.001 & 0.004 & 0.086 \\
$20-29$ & 0.015 & 0.012 & 0.027 & 0.011 & 0.006 & 0.029 & 0.005 & 0.004 & 0.010 & 0.001 & 0.003 & 0.123 \\
$30-39$ & 0.004 & 0.006 & 0.010 & 0.004 & 0.004 & 0.013 & 0.003 & 0.002 & 0.005 & 0.002 & 0.002 & 0.055 \\
$40-49$ & 0.003 & 0.004 & 0.004 & 0.004 & 0.003 & 0.009 & 0.005 & 0.004 & 0.003 & 0.001 & 0.001 & 0.041 \\
50 & 0.015 & 0.014 & 0.024 & 0.011 & 0.010 & 0.071 & 0.016 & 0.018 & 0.036 & 0.008 & 0.008 & 0.231 \\
$51-60$ & 0.001 & 0.004 & 0.005 & 0.003 & 0.003 & 0.012 & 0.006 & 0.007 & 0.012 & 0.001 & 0.003 & 0.057 \\
$61-70$ & 0.000 & 0.002 & 0.002 & 0.001 & 0.003 & 0.010 & 0.005 & 0.008 & 0.015 & 0.003 & 0.003 & 0.052 \\
$71-80$ & 0.004 & 0.005 & 0.006 & 0.003 & 0.005 & 0.027 & 0.009 & 0.012 & 0.042 & 0.011 & 0.014 & 0.138 \\
$81-90$ & 0.001 & 0.000 & 0.001 & 0.001 & 0.001 & 0.006 & 0.003 & 0.002 & 0.010 & 0.006 & 0.005 & 0.036 \\
$91-100$ & 0.004 & 0.004 & 0.002 & 0.001 & 0.001 & 0.007 & 0.001 & 0.003 & 0.014 & 0.009 & 0.020 & 0.066 \\
\hline all & 0.098 & 0.080 & 0.112 & 0.050 & 0.042 & 0.221 & 0.060 & 0.065 & 0.162 & 0.046 & 0.069 & 1.000
\end{tabular}


Table 3: Expectations of Positive Nominal Equity Return (by attribute)

\begin{tabular}{|c|c|c|c|c|c|c|c|c|}
\hline \multirow{3}{*}{ attribute } & \multicolumn{4}{|c|}{ Michigan Data } & \multicolumn{4}{|c|}{ SEE Data } \\
\hline & \multicolumn{2}{|c|}{ sample size ${ }^{\mathrm{a}}$} & \multirow[t]{2}{*}{ mean } & \multirow[t]{2}{*}{ std dev } & \multicolumn{2}{|c|}{ sample size ${ }^{a}$} & \multirow[t]{2}{*}{ mean } & \multirow{2}{*}{ std dev } \\
\hline & $\mathrm{N}$ & NR & & & $\mathrm{N}$ & NR & & \\
\hline all persons & 7411 & $(609)$ & 46.4 & 29.4 & 1212 & $(439)$ & 68.0 & 27.5 \\
\hline male & 3363 & $(175)$ & 50.2 & 30.0 & 625 & (149) & 68.7 & 26.9 \\
\hline female & 4048 & $(434)$ & 43.2 & 28.5 & 587 & $(290)$ & 67.3 & 28.1 \\
\hline non-Hisp. white & 5833 & $(426)$ & 47.3 & 29.3 & 993 & $(348)$ & 68.8 & 26.8 \\
\hline non-Hisp. black & 610 & (76) & 41.6 & 28.9 & 85 & (33) & 64.7 & 30.8 \\
\hline Hispanic & 547 & (64) & 44.9 & 29.9 & - & - & - & - \\
\hline American Indian & 70 & (4) & 36.4 & 28.3 & 10 & (9) & 58.5 & 36.1 \\
\hline Asian & 160 & (11) & 45.4 & 31.7 & 29 & (6) & 60.8 & 29.7 \\
\hline age $18-34$ & 1804 & $(82)$ & 51.0 & 26.7 & 361 & (91) & 68.9 & 25.3 \\
\hline age $35-49$ & 2520 & (132) & 48.4 & 28.4 & 411 & (98) & 70.0 & 26.9 \\
\hline age $50-64$ & 1863 & $(125)$ & 45.9 & 30.9 & 265 & (114) & 67.8 & 27.6 \\
\hline age $65+$ & 1178 & $(261)$ & 36.1 & 30.2 & 152 & (122) & 62.3 & 31.8 \\
\hline schooling $0-12$ & 2494 & $(375)$ & 40.1 & 28.6 & 151 & (140) & 59.1 & 31.6 \\
\hline schooling 13-15 & 2116 & (126) & 46.9 & 29.0 & 382 & (139) & 68.8 & 27.8 \\
\hline schooling $16+$ & 2745 & (92) & 51.6 & 29.2 & 607 & (129) & 70.5 & 25.0 \\
\hline
\end{tabular}

${ }^{\mathrm{a}} \mathrm{N}=$ frequency of response to question PNR; NR = frequency of non-response 
Table 4: Best Linear Predictors of Expectations of Positive Nominal Equity Return

\begin{tabular}{|c|c|c|c|c|}
\hline \multirow[b]{2}{*}{ Covariate } & \multicolumn{2}{|c|}{ Michigan Data $(\mathrm{N}=7169)$} & \multicolumn{2}{|c|}{ SEE Data $(\mathrm{N}=1035)$} \\
\hline & coefficient & (std error) & coefficient & (std error) \\
\hline Constant & 45.33 & $(1.91)$ & 62.14 & $(3.25)$ \\
\hline male & 6.27 & $(0.67)$ & 1.30 & $(1.66)$ \\
\hline Non-Hispanic black & -5.94 & $(1.21)$ & -2.72 & $(3.23)$ \\
\hline Hispanic & -3.85 & $(1.29)$ & - & - \\
\hline American Indian & -12.27 & $(3.38)$ & -9.99 & $(8.44)$ \\
\hline Asian & -7.64 & $(2.28)$ & -8.45 & $(5.13)$ \\
\hline age $35-49$ & -3.34 & $(0.88)$ & 0.66 & $(2.09)$ \\
\hline age $50-64$ & -6.71 & $(0.95)$ & -2.45 & $(2.33)$ \\
\hline age $65+$ & -15.16 & $(1.09)$ & -6.47 & $(2.78)$ \\
\hline schooling 13-15 & 5.13 & $(0.85)$ & 7.61 & $(2.76)$ \\
\hline schooling $16+$ & 9.70 & $(0.81)$ & 9.60 & $(2.64)$ \\
\hline Feb-00 - May-00 & & & 3.13 & $(2.17)$ \\
\hline Sep-00 - Mar-01 & & & -2.50 & $(2.02)$ \\
\hline Jul-02 & -6.77 & $(2.45)$ & & \\
\hline Aug-02 & -5.04 & $(2.46)$ & & \\
\hline Sep-02 & -8.53 & $(2.42)$ & & \\
\hline Oct-02 & -7.41 & $(2.44)$ & & \\
\hline Nov-02 & -2.69 & $(2.42)$ & & \\
\hline Dec-02 & -5.71 & $(2.47)$ & & \\
\hline Jan-03 & -4.72 & $(2.47)$ & & \\
\hline Feb-03 & -8.18 & $(2.43)$ & & \\
\hline Mar-03 & -3.97 & $(2.44)$ & & \\
\hline Apr-03 & -6.11 & $(2.47)$ & & \\
\hline May-03 & -1.79 & $(2.43)$ & & \\
\hline Jun-03 & 1.61 & $(2.46)$ & & \\
\hline Jul-03 & -0.13 & $(2.43)$ & & \\
\hline Aug-03 & 1.04 & $(2.46)$ & & \\
\hline Sep-03 & -0.23 & $(2.44)$ & & \\
\hline Oct-03 & 1.37 & $(2.44)$ & & \\
\hline
\end{tabular}




\begin{tabular}{c|ll|} 
Nov-03 & 2.72 & $(2.46)$ \\
Dec-03 & 3.69 & $(2.42)$ \\
Jan-04 & 4.47 & $(2.39)$ \\
Feb-04 & 4.91 & $(2.44)$ \\
Mar-04 & 7.23 & $(2.43)$ \\
Apr-04 & 1.51 & $(2.41)$ \\
May-04 & 5.35 & $(2.42)$ \\
Jun-04 & 4.65 & $(2.40)$ \\
Jul-04 & 4.58 & $(2.44)$ \\
Aug-04 & 6.71 & $(2.42)$
\end{tabular}


Table 5: Fitted SEE Subjective Distributions of Nominal Equity Returns

\begin{tabular}{|c|c|c|c|c|c|}
\hline & & & & quantile & \\
\hline & Mean & Std. Dev. & 0.25 & 0.50 & 0.75 \\
\hline Wave $12(\mathrm{~N}=343)$ & & & & & \\
\hline$\mu$ & 0.33 & 0.64 & 0.03 & 0.17 & 0.50 \\
\hline$\sigma$ & 0.59 & 0.75 & 0.18 & 0.36 & 0.69 \\
\hline Wave $13(\mathrm{~N}=264)$ & & & & & \\
\hline$\mu$ & 0.40 & 0.63 & 0.08 & 0.28 & 0.60 \\
\hline$\sigma$ & 0.68 & 0.87 & 0.22 & 0.43 & 0.76 \\
\hline Wave $14(\mathrm{~N}=379)$ & & & & & \\
\hline$\mu$ & 0.36 & 0.68 & 0.03 & 0.20 & 0.47 \\
\hline$\sigma$ & 0.65 & 0.80 & 0.19 & 0.39 & 0.78 \\
\hline All Waves $(\mathrm{N}=986)$ & & & & & \\
\hline$\mu$ & 0.36 & 0.65 & 0.04 & 0.20 & 0.50 \\
\hline$\sigma$ & 0.63 & 0.80 & 0.19 & 0.39 & 0.74 \\
\hline
\end{tabular}




\section{2}

Table 6: Responses to Question PNR (percentage of responses)

\begin{tabular}{|c|c|c|}
\hline Percent Chance & Michigan Data & SEE Data \\
\hline 0 & 5.02 & 2.27 \\
\hline 1 & 0.55 & 2.67 \\
\hline 2 & 1.1 & 0.41 \\
\hline 3 & 0.64 & 0.16 \\
\hline 4 & 0.2 & 0 \\
\hline 5 & 3.2 & 0.57 \\
\hline $6-9$ & 0.5 & 0.16 \\
\hline 10 & 7.14 & 1.62 \\
\hline $11-14$ & 0.21 & 0.16 \\
\hline 15 & 0.98 & 0.32 \\
\hline $16-19$ & 0.16 & 0 \\
\hline 20 & 8.7 & 1.86 \\
\hline $21-24$ & 0.07 & 0.08 \\
\hline 25 & 3.39 & 1.22 \\
\hline $26-29$ & 0.05 & 0 \\
\hline 30 & 4.65 & 2.11 \\
\hline $31-34$ & 0.06 & 0.08 \\
\hline 35 & 0.59 & 0.16 \\
\hline $36-39$ & 0.04 & 0 \\
\hline 40 & 3.95 & 2.59 \\
\hline $41-44$ & 0.01 & 0 \\
\hline 45 & 0.33 & 0.41 \\
\hline $46-49$ & 0.04 & 0 \\
\hline 50 & 22.49 & 20.18 \\
\hline $51-54$ & 0.06 & 0.08 \\
\hline 55 & 0.3 & 0.08 \\
\hline $56-59$ & 0.03 & 0 \\
\hline 60 & 5.49 & 3.73 \\
\hline $61-64$ & 0.03 & 0 \\
\hline 65 & 0.78 & 0.73 \\
\hline $66-69$ & 0.06 & 0 \\
\hline 70 & 4.73 & 4.46 \\
\hline $71-74$ & 0.06 & 0.16 \\
\hline 75 & 4.89 & 8.75 \\
\hline $76-79$ & 0.09 & 0 \\
\hline 80 & 9.14 & 11.59 \\
\hline $81-84$ & 0.03 & 0.08 \\
\hline 85 & 0.77 & 1.62 \\
\hline $86-89$ & 0.04 & 0 \\
\hline 90 & 2.94 & 9.81 \\
\hline $91-94$ & 0.03 & 0 \\
\hline 95 & 0.48 & 4.05 \\
\hline 96 & 0 & 0 \\
\hline 97 & 0.03 & 0.08 \\
\hline 98 & 0.06 & 1.7 \\
\hline 99 & 0.13 & 0.65 \\
\hline 100 & 5.76 & 15.4 \\
\hline
\end{tabular}


Table 7: Type-Specific Percent-Chance of Positive Nominal Return

\begin{tabular}{c|ccc}
\multirow{2}{*}{ month } & \multicolumn{3}{|c}{ Response to Question PNR } \\
& Type RW & Type P & Type MR \\
\hline Jun-02 & 70.1 & 18.4 & 98.3 \\
Jul-02 & 70.1 & 10.5 & 99.2 \\
Aug-02 & 70.1 & 22.9 & 98.3 \\
Sep-02 & 70.1 & 17.2 & 98.8 \\
Oct-02 & 70.1 & 22.8 & 97.6 \\
Nov-02 & 70.1 & 16.8 & 98.0 \\
Dec-02 & 70.1 & 14.3 & 99.1 \\
Jan-03 & 70.1 & 13.3 & 99.2 \\
Feb-03 & 70.1 & 7.9 & 99.2 \\
Mar-03 & 70.1 & 10.2 & 99.4 \\
Apr-03 & 70.1 & 18.0 & 97.0 \\
May-03 & 70.1 & 25.9 & 94.5 \\
Jun-03 & 70.1 & 46.3 & 87.3 \\
Jul-03 & 70.1 & 68.3 & 71.8 \\
Aug-03 & 70.1 & 65.0 & 69.1 \\
Sep-03 & 70.1 & 81.1 & 43.0 \\
Oct-03 & 70.1 & 80.5 & 50.8 \\
Nov-03 & 70.1 & 78.8 & 63.0 \\
Dec-03 & 70.1 & 88.7 & 34.1 \\
Jan-04 & 70.1 & 92.5 & 23.2 \\
Feb-04 & 70.1 & 93.9 & 17.1 \\
Mar-04 & 70.1 & 90.4 & 22.2 \\
Apr-04 & 70.1 & 89.7 & 46.1 \\
May-04 & 70.1 & 87.9 & 56.0 \\
Jun-04 & 70.1 & 87.1 & 54.3 \\
Jul-04 & 70.1 & 75.4 & 66.7 \\
Aug-04 & 70.1 & 69.5 & 70.0 \\
& & &
\end{tabular}


Table 8: Upper Bounds on Prevalence of Types, Michigan Data

\begin{tabular}{c|cc|cc|cc} 
Type & \multicolumn{2}{|c|}{$\begin{array}{c}\text { Pooled Data } \\
(\mathrm{N}=8727)\end{array}$} & \multicolumn{2}{c|}{$\begin{array}{c}\text { 1 Interview } \\
(\mathrm{N}=4842)\end{array}$} & \multicolumn{2}{c}{$\begin{array}{c}2 \text { Interviews } \\
(\mathrm{N}=3885) \\
\text { Exact }\end{array}$} \\
& Exact & Near & Exact & Near & Near \\
\hline RW & .026 & .136 & .044 & .187 & .006 & .076 \\
P & .053 & .127 & .091 & .197 & .010 & .045 \\
MR & .055 & .089 & .092 & .141 & .011 & .028 \\
RW + P & .077 & .229 & .130 & .327 & .015 & .116 \\
RW + MR & .076 & .209 & .128 & .300 & .017 & .104 \\
P + MR & .105 & .207 & .178 & .322 & .021 & .073 \\
RW + P + MR & .127 & .302 & .213 & .439 & .026 & .144
\end{tabular}

